\title{
Unexpected Vesicoureteral Reflux Into a Nonfunctioning Transplant Kidney on Renal Scintigraphy
}

\author{
Adam Cruz, BS, * Daniel J. Wale, DO, $+\neq$ Ka Kit Wong, MBBS, $†$ \\ Brett M. Arnkoff, MD, $\S$ and Benjamin L. Viglianti, MD, PhD $†$ t
}

\begin{abstract}
Vesicoureteral reflux after renal transplantation is associated with increase risk of urinary tract infections, renal scarring, and graft failure. We describe a case of a 46-year-old woman with 2 transplant kidneys, one functioning and another nonfunctioning, presenting with pelvic pain after a bilateral periureteral bulking procedure. Diuretic renography was performed to exclude iatrogenic ureteral obstruction. This showed a normally functioning transplant kidney without obstruction and subsequent vesicoureteral reflux into the collecting system of the nonfunctioning transplant kidney. This inadvertent indirect nuclear cystogram illustrates an unusual imaging presentation of a common disease process requiring further treatment.
\end{abstract}

Key Words: vesicoureteral reflux, indirect nuclear cystography, nuclear renal transplant evaluation

(Clin Nucl Med 2018;43: 533-534)

Received for publication February 19, 2018; revision accepted March 14, 2018. From the *University of Michigan Medical School; †Department of Radiology, University of Michigan; and $\$$ Nuclear Medicine Service, and §Radiology Service, VA Medical Center, Ann Arbor, MI.

Conflicts of interest and sources of funding: none declared.

Correspondence to: Daniel J. Wale, DO, 2215 Fuller Rd, D748, Ann Arbor, MI 48105. E-mail: dwale@med.umich.edu.

Copyright (C) 2018 Wolters Kluwer Health, Inc. All rights reserved.

ISSN: 0363-9762/18/4307-0533

DOI: $10.1097 /$ RLU.0000000000002101

\section{REFERENCES}

1. Molenaar NM, Minnee RC, Bemelman FJ, et al. Vesicoureteral reflux in kidney transplantation. Prog Transplant. 2017;27:196-199.

2. Margreiter M, Györi GP, Böhmig GA, et al. Value of routine voiding cystourethrography after renal transplantation. Am J Transplant. 2013;13: 130-135.

3. Cendron M. Reflux nephropathy. J Pediatr Urol. 2008;4:414-421.

4. Springer A, Subramaniam R. Relevance of current guidelines in the management of VUR. Eur J Pediatr. 2014;173:835-843.

5. Fettich J, Colarinha P, Fischer S, et al. Guidelines for direct radionuclide cystography in children. Eur J Nucl Med Mol Imaging. 2003;30:B39-B44.

6. Gordon I, Colarinha P, Fettich J, et al. Guidelines for indirect radionuclide cystography. Eur J Nucl Med. 2001;28:BP16-BP20.

7. Lebowitz RL, Olbing H, Parkkulainen KV, et al. International system of radiographic grading of vesicoureteric reflux. International Reflux Study in Children. Pediatr Radiol. 1985;15:105-109.

8. Willi U, Treves S. Radionuclide voiding cystography. Urol Radiol. 1983;5: 161-173. 175

9. Tripathi M, Chandrashekar N, Kumar R, et al. Reflux in native kidneys mimicking urine leak postrenal transplant. Clin Nucl Med. 2005;30:344-346.

10. Karacalioglu O, Ilgan S, Arslan N, et al. Diagnostic difficulty in interpretation of Tc-99m MAG3 dynamic renal scan: intrarenal reflux or delayed concentration function? Clin Nucl Med. 2004;29:382-385.

11. Tsuchimochi S, Nakajo M, Tanabe H, et al. Unilateral vesicoureteral reflux detected by diuretic renography without voiding. Clin Nucl Med. 2003;28: 228-229.

12. Fonseca RB, Duarte PS, Susuki L. Vesicoureteral reflux in a patient with complete ureteral duplication detected on Tc-99m DTPA renography. Clin Nucl Med. 2003;28:498-500. 


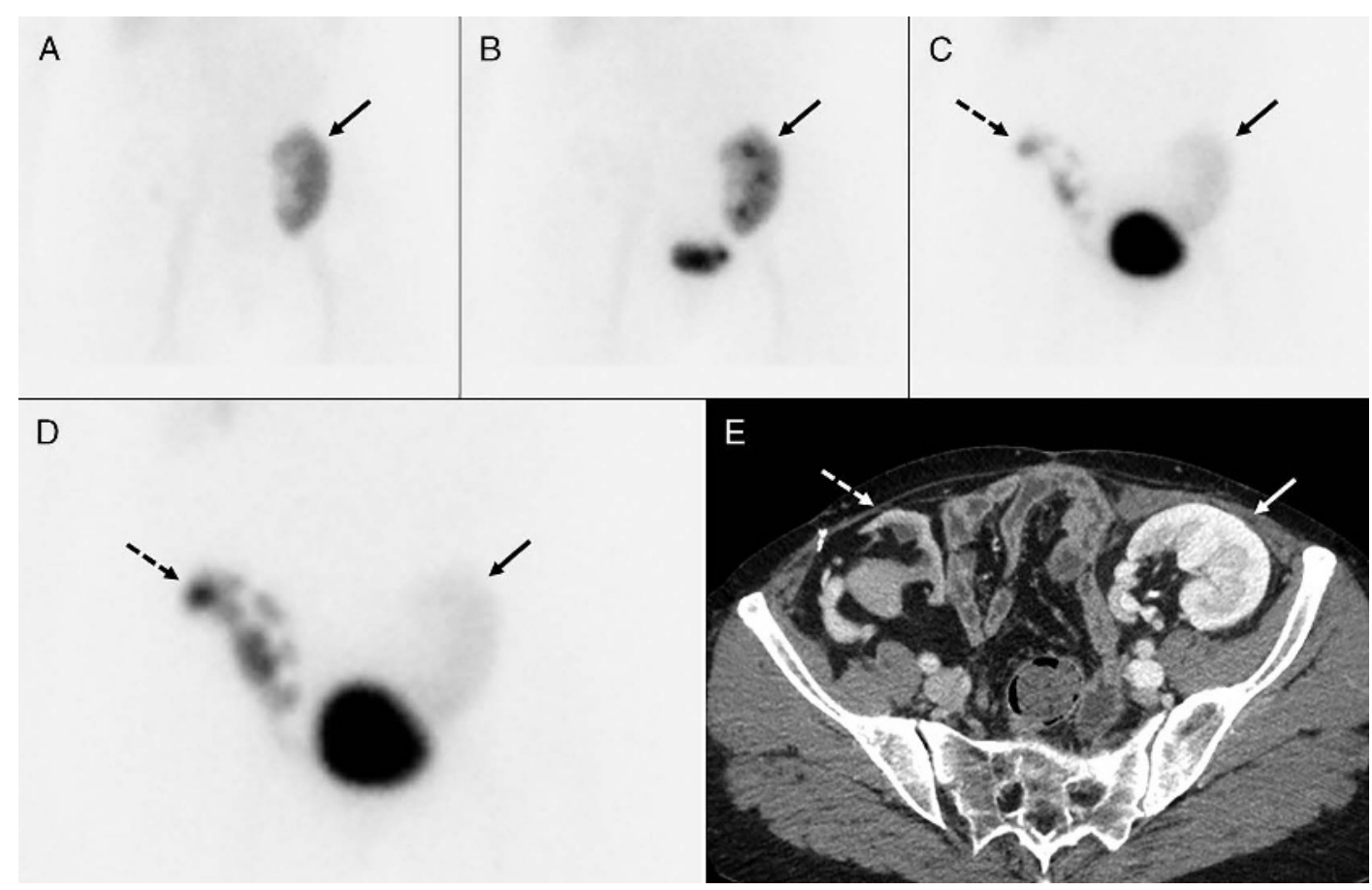

FIGURE 1. A 46-year-old woman with a history of renal transplants underwent dynamic renal scintigraphy using

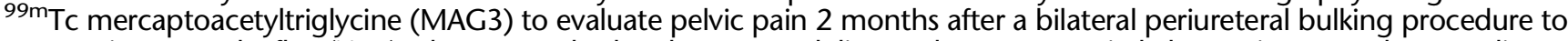
treat vesicoureteral reflux (VUR). The woman had end-stage renal disease due to congenital obstructive uropathy complicated by multiple infections and underwent an initial renal transplant in the right pelvis in the early 1990s, at which time her native kidneys were removed. This transplant worked well for almost 17 years, when it became nonfunctional and a second transplant kidney was placed in the left pelvis. Recently, she has had multiple episodes of urinary tract infections including one incident leading to sepsis thought to be related to VUR that was treated with periureteral bulking. Early dynamic imaging from the renogram (A) demonstrates expected radiopharmaceutical uptake by the functioning transplant kidney in the left pelvis (solid black arrows). Subsequent imaging (B) shows normal excretion of the radiopharmaceutical into the left collecting system and filling of the urinary bladder. As the urinary bladder distends (C, D), the radiopharmaceutical refluxes into a dilated collecting system of a right pelvic transplant kidney (dashed black arrows). The transplanted right kidney is not visualized on scintigraphy as it is nonfunctioning, resulting in this unusual renogram. Contrast-enhanced CT (E) confirms the pelvic location of the transplant kidneys including the functioning left kidney (solid white arrow) as well as the nonfunctioning right kidney (dashed white arrow) demonstrating a dilated collecting system. Although the reported incidence varies, postrenal transplantation VUR is a relatively common complication. ${ }^{1,2}$ Vesicoureteral reflux predisposes patients to complications such as infections and renal graft parenchymal injury and failure. ${ }^{3}$ Treatments for VUR include clinical monitoring, prophylactic antibiotics, endoscopic periureteral bulking procedures, and surgery. ${ }^{4}$ Vesicoureteral reflux can be evaluated using nuclear cystography, in which a radiotracer is directly injected into the bladder via catheter. ${ }^{5}$ Because of normal activity in the collecting systems, it is unusual to incidentally detect VUR on traditional nuclear renograms, although evaluation of VUR using an additional delayed voiding phase after a nuclear renogram has been described, often referred to as indirect nuclear cystography. ${ }^{6}$ The five level International Grading System is used to report the severity of VUR on radiological voiding cystourethrography. ${ }^{7}$ However, a simpler 3-level grading scale is often used in nuclear medicine with mild (grade 1) reflux extending to the level of the ureter, moderate (grade 2) reflux extending into a nondilated renal pelvis, and severe (grade 3) reflux extending into the renal pelvis with a dilated/tortuous collecting system. ${ }^{5,8}$ Although unusual to incidentally detect VUR on renography, similar cases have been described with unexpected VUR detected on renograms in the native kidneys of a renal transplant patient, into nonfunctioning and poorly functioning native kidneys in nontransplant patients, and into a lower pole moiety of a duplex collecting system..$^{9-12}$ Although inadvertent, the diagnosis of VUR in this woman was clinically important as it indicated continuing reflux despite bilateral bulking procedures that was significant, given her history of urinary tract infections and sepsis. 